\title{
Oculocardiac reflex: an unusual trigger during dental surgery
}

\author{
Vivek Arora, Alex Lee \\ VA Puget Sound Health Care System, Department of Anesthesiology \& Pain Medicine, University of Washington, Seattle, WA, USA
}

\begin{abstract}
J Korean Assoc Oral Maxillofac Surg 2021;47:335-336)
The oculocardiac reflex is a trigeminal-vagal reflex that manifests as cardiac arrythmias, most often bradycardia. The reflex can be triggered by manipulation of periorbital structures and unintended pressure on the bulbus oculi maxillofacial procedures. In this brief communication, we describe an unusual trigger of the oculocardiac reflex during maxillofacial surgery that resulted in severe bradycardia. This case highlights the need for careful securement of medical devices and attention to surgical technique to avoid undue pressure on draped fascial structures.
\end{abstract}

Key words: Nasotracheal tube, Bradycardia, Oculocardiac reflex

[paper submitted 2020. 12. 25 / revised 2021. 2. 17 / accepted 2021. 2. 17]

Oculocardiac reflex (OCR) is a trigeminal-vagal reflex, also known as the Aschner reflex. It can be triggered by the manipulation of periorbital structures during surgery, most often in ophthalmological, oral maxillofacial, and neurosurgical procedures ${ }^{1,2}$. For certain oral maxillofacial surgeries, a Ring-Adair-Elwyn (RAE) nasotracheal tube is frequently used to keep the endotracheal (ET) tube away for the surgeon's field. Adequate fixation of a nasal RAE ET tube is necessary to 1) prevent slippage and unintended extubation and 2) avoid fascial injury, including nasal alar cartilage damage $^{3}$. The curvature preformed on the patient end of the nasal RAE ET tube needs to be adequately supported with either commercially available headwear devices or other custommade alternatives such as surgical scrub brushes, surgical gauze, foam pieces, and folded surgical towels positioned over the forehead ${ }^{4}$. As shown in Fig. 1, this support under the tracheal tube, if not adequately secured, has the potential to slip onto the patients face and fill the orbit concavity. Note that when working under surgical drapes, this can go unno-

\section{Vivek Arora \\ VA Puget Sound Health Care System, Department of Anesthesiology \& Pain Medicine, University of Washington, 1660 Columbian Way, Seattle, WA 98107, USA \\ TEL: +1-206-764-2574 \\ E-mail:Varora2@uw.edu \\ ORCID: https://orcid.org/0000-0003-1544-6032}

(c) This is an open-access article distributed under the terms of the Creative Commons Attribution Non-Commercial License (http://creativecommons.org/ licenses/by-nc/4.0/), which permits unrestricted non-commercial use, distribution, and reproduction in any medium, provided the original work is properly cited.

Copyright (C) 2021 The Korean Association of Oral and Maxillofacial Surgeons. ticed. This image displays the causative mechanism of OCR in a 48-year-old male, who with no underlying cardiorespiratory disease, developed severe bradycardia during dental implant placement under general anesthesia with nasal RAE ET intubation. During the procedure, the heart rate gradually slowed from 80 to $50 \mathrm{bpm}$, culminating in an episode of severe bradycardia (heart rate, 20-30 bpm) and hypotension. The surgical procedure was halted, and preparations were made to commence chest compressions. Concurrently, 0.2 $\mathrm{mg}$ intravenous glycopyrrolate was administered, leading to
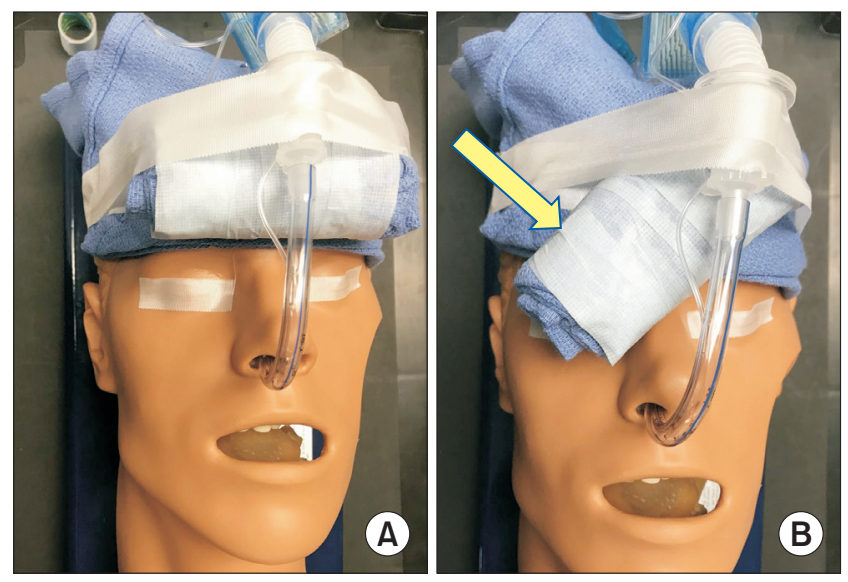

Fig. 1. A. A folded surgical towel is placed on the forehead to support the Ring-Adair-Elwyn (RAE) tube. B. The folded towel is noted to have slipped (arrow) from under the RAE tube into the orbital cavity transmitting pressure from the surgeon's hand above the drapes on to the globe.

Vivek Arora et al: Oculocardiac reflex: an unusual trigger during dental surgery. J Korean Assoc Oral Maxillofac Surg 2021 
the resolution of bradycardia and hypotension. At the time of the incident, the cause of critical bradycardia was unclear. At the end of the procedure following removal of the surgical drapes, a folded surgical towel was noted to have slipped onto the orbit, thus transmitting pressure from the surgeon's hand above the drapes onto the globe. This case illustrates a potential trigger for OCR, which can present as severe bradycardia during dental surgery with a nasal RAE intubation. This reiterates the need for meticulous techniques, not only while securing an ET tube but also on the oral surgeon's behalf, to prevent undue pressure on draped facial structures.

\section{ORCID}

Vivek Arora, https://orcid.org/0000-0003-1544-6032

Alex Lee, https://orcid.org/0000-0002-3224-0434

\section{Authors' Contributions}

V.A. participated in data collection and wrote the manuscript. V.A. and A.L. participated in the study design and coordination and helped to draft the manuscript. All authors read and approved the final manuscript.

\section{Conflict of Interest}

No potential conflict of interest relevant to this article was reported.

\section{References}

1. Brasileiro BF, Sickels JEV, Cunningham LL. Oculocardiac reflex in an adult with a trapdoor orbital floor fracture: case report, literature review, and differential diagnosis. J Korean Assoc Oral Maxillofac Surg 2020;46:428-34. https://doi.org/10.5125/jkaoms.2020.46.6.428

2. Doyle DJ, Mark PW. Reflex bradycardia during surgery. Can J Anaesth 1990;37:219-22. https://doi.org/10.1007/BF03005473

3. Yamamoto T, Flenner M, Schindler E. Complications associated with nasotracheal intubation and proposal of simple countermeasure. Anaesthesiol Intensive Ther 2019;51:72-3. https://doi. org/10.5603/AIT.a2019.0002

4. Farbod F, Tuli P, Robertson BF, Jackson IT. Endotracheal tube fixation methods for optimal stability: a comparison of adhesive tape, suture, and tape-suture fixation. J Craniofac Surg 2010;21:1250-1. https://doi.org/10.1097/SCS.0b013e3181e20860

How to cite this article: Arora V, Lee A. Oculocardiac reflex: an unusual trigger during dental surgery. J Korean Assoc Oral Maxillofac Surg 2021;47:335-336. https://doi.org/10.5125/jkaoms.2021.47.4.335 